\title{
EDUCAÇÃO NAS LEIS ORGÂNICAS DOS MUNICÍPIOS FLUMINENSES: POUCA ORIGINALIDADE E MUITA CÓPIA
}

\author{
NICHOLAS DAVIES \\ Professor da Faculdade de Educação da Universidade Federal Fluminense - Niterói, RJ \\ nicholas@pq.cnpq.br
}

\section{RESUMO}

O artigo examina as disposições educacionais nas Leis Orgânicas dos 92 municípios fluminenses e constata que elas apresentam pouca originalidade, pois são principalmente cópias das Constituições Federal e Estadual do Rio de Janeiro e de modelos fornecidos por consultorias legislativas ou partidos políticos. Observa que a maioria contém as mesmas formulações e os mesmos equívocos das Constituições e que existem as que até copiam errado artigos dos textos base, o que provavelmente não ocorreria se os vereadores tivessem elaborado as leis de maneira autônoma. Algumas Leis Orgânicas apresentam, contudo, contribuições originais, tanto positivas (aumento do percentual mínimo da receita orçamentária municipal para a educação) quanto negativas (redução desse percentual através de emendas). O estudo mostra como é frágil o exercício concreto da autonomia municipal na elaboração dessas leis em uma perspectiva democrática e como é ilusória a ideia de muitos que no âmbito local o exercício da cidadania é mais fácil.

RIO DE JANEIRO - LEGISLAÇÃO - MUNICÍPIOS - POLÍTICAS EDUCACIONAIS

\section{ABSTRACT}

EDUCATION IN RIO DE JANEIRO MUNICIPALITIES' CONSTITUTIONS: LITTLE ORIGINALITY AND AMPLE COPY. The article examines the educational provisions in the constitutions of the 92 municipalities of the State of Rio de Janeiro and finds that they show little originality, for they are mainly a copy of the Brazilian Federal Constitution, the State Constitution of Rio de Janeiro and of models sold by consultancies especialized in the sale of legal packages or supplied by political parties. It puts forward the argument that many municipal constitutions are copies of such models because they repeat the same formulations, which would not probably occur if the councillors had drafted the municipal constitutiosn autonomously. However, a number of municipal constitutions contain original contributions, both positive (increasing the minimum percentage of taxes to education) and negative (reduction of this percentage by means of amendments to the municipal constitutions. This indicates the fragility of the concrete exercise of municipal autonomy in the drafting of municipal constitutions from a democratic perspective and the illusion that many have that the exercise of citizenship is easier on a local level. RIO DEJANEIRO - EDUCATIONAL LEGISLATION - MUNICIPALITIES - EDUCATIONAL POLICIES 
O objetivo inicial deste estudo foi fazer um levantamento das disposições educacionais nas Leis Orgânicas - LOs - dos 92 municípios do Estado do Rio de Janeiro, nem sempre facilmente acessíveis, para que educadores pudessem informar-se sobre elas e assim exercer pelo menos esse aspecto da cidadania, tão proclamada e tão pouco praticada.

Foram compiladas as disposições sobre a educação não apenas no capítulo específico, mas em todo o corpo das LOs, e ainda as emendas introduzidas desde sua promulgação em 1990 (para a maioria dos municípios) ou em 1993 e 1997 (para os que se emanciparam após 1990) até 2007 e as decisões judiciais suspendendo a vigência das disposições.

Para obter os textos das LOs, recorri inicialmente ao sítio do Tribunal de Contas do Estado (www.tce.rj.gov.br). Visto que continham muitas falhas, fui obrigado a consultar a biblioteca do TCE, onde encontrei edições originais das LOs, mas faltavam textos atualizados com todas as alterações posteriores à promulgação. Essas duas fontes constituem a base da pesquisa. Realizei outras buscas em sítios de prefeituras ou câmaras municipais ou solicitei a elas edições impressas atualizadas, mas só tive sucesso em poucos casos e, mesmo assim, as versões fornecidas não eram necessariamente confiáveis. Por exemplo, a LO de São Gonçalo disponível no sítio da prefeitura em novembro de 2005 não incorporava uma modificação de dezembro de 2002.

Várias são as justificativas para este estudo, além de verificar a possível influência cidadã na elaboração das LOs. A primeira é que ele não havia sido feito até hoje. Outra é que, como tenho observado ao longo dos anos, os profissionais da educação não parecem ter conhecimento das disposições da LO do município em que trabalham. Outra é que são poucos os estudos sobre a educação nas LOs. O levantamento feito por Souza e Faria (2005), que cobre o período de 1995 a 2002, registra apenas quatro trabalhos relacionados ao tema: o de Damasceno e Correa (1996) no Pará; o de Boaventura (1996) em 47 municípios baianos; o de Catani e Oliveira (1993) em 20 municípios paulistas; e o de Sandano (1997) em Sorocaba (SP).

Nossa principal constatação é que, além dos inúmeros lapsos de português (grafia, pontuação, redação deficiente), as disposições educacionais são basicamente cópias, às vezes com erros, em proporções variáveis, da Constituição Federal - CF -, de 1988 e da Constituição Estadual - CE -, de 1989. Outra constatação é que muitas disposições aparentemente novas são, na 
verdade, cópias de modelos de LO, pois as mesmas formulações e os mesmos equívocos se repetem em dezenas delas, o que permite levantar a hipótese de que os modelos tenham sido fornecidos por consultorias especializadas em vender "pacotes" legislativos ou por partidos políticos. No máximo, os vereadores se limitaram a selecionar itens desses pacotes e acrescentar uma ou outra disposição para atender a algum interesse pessoal, local ou de grupos. Outra hipótese é que pelo menos algumas LOs (não muitas) se limitaram a copiar outras LOs em elaboração ou já promulgadas. Uma terceira constatação é que, embora muitas LOs contenham disposições não repetidas em outras, a proporção delas no total não chega a ser significativa.

Tudo isso permite inferir que é mínimo o exercício da autonomia da imensa maioria dos municípios, de seus cidadãos e de suas entidades no plano legislativo, em particular no que se refere às disposições sobre a educação nas LOs, o que pode ser atribuído ao desinteresse, desconhecimento, incompetência ou comodismo dos vereadores e da população. No entanto, algumas formulações das LOs e suas alterações desde 1990 mostram que a falta de autonomia e o comodismo desaparecem quando se trata de defender o interesse dos vereadores ou de entidades ou grupos que supostamente representam. Por exemplo, I I LOs que previam um percentual mínimo maior que 25\% da receita de impostos para a educação tiveram esse percentual reduzido, embora as necessidades de mais recursos para a educação tenham aumentado.

Nas seções seguintes reproduzo e comento sucessivamente: exemplos de LOs que copiaram equivocadamente a Constituição Federal; exemplos de LOs que não souberam copiar a Constituição Estadual; erros e formulações de LOs que indicam que provavelmente foram copiadas de modelos fornecidos por consultorias legislativas ou partidos políticos; erros e contradições que não resultam de cópias equivocadas das Constituições e dos modelos; disposições originais (positivas e negativas) em algumas LOs. Vale lembrar que a relação a seguir não é exaustiva.

\section{CÓPIAS EQUIVOCADAS DA CONSTITUIÇÃO FEDERAL}

Várias LOs copiaram a Constituição Federal de 1988 com erros ou sem as necessárias adaptações e supressões. Por exemplo, ao repetirem o inciso VI do art. 30 - "Compete aos Municípios manter, com a cooperação técnica 
e financeira da União e do Estado, programas de educação pré-escolar e de ensino fundamental" -, acrescentaram "privativamente" ao verbo "manter", provavelmente copiando a formulação do caput do Art. 22. Com isso, distorceram o significado original do texto, dando a entender que só os Municípios podem manter programas de educação pré-escolar e de ensino fundamental. Ora, o fato de os Municípios manterem tais programas não impede que União e Estados também o façam. É muito provável que esse equívoco resulte de cópia de modelo fornecido por consultorias legislativas, pois ele aparece nas LOs de I 3 Municípios: Campos, Carmo, Comendador Levy Gasparian, Laje de Muriaé, Macaé, Maricá, Petrópolis, Rio Claro, Rio das Flores, Santa Maria Madalena, São Fidélis, Saquarema e Três Rios.

Outra distorção se refere ao inciso XVI do art. 37, que veda "a acumulação remunerada de cargos públicos, exceto, quando houver compatibilidade de horários, no caso de cargos públicos de professor". Quase todas as LOs que copiaram esse inciso erraram ao não inserir a vírgula depois de "exceto", o que muda totalmente o significado. $\bigcirc$ erro provavelmente tem origem na Constituição Estadual, que também omitiu a vírgula.

Dezenas de LOs se equivocaram ao copiar o inciso II do art. 208 da CF de 1988, que trata do dever do Estado de assegurar "a progressiva extensão da obrigatoriedade e gratuidade no ensino médio". Ora, sabe-se que o ensino médio não é dever dos Municípios, mas sua prioridade é o ensino fundamental e a pré-escola e, a partir da Emenda Constitucional I 4 de 1996, a educação infantil.

Outro equívoco cometido por muitas LOs, e também pela Constituição Estadual, refere-se à disposição sobre o salário-educação, que é tributo federal e, portanto, da competência exclusiva da Constituição Federal.

Um exemplo de cópia sem a necessária adaptação diz respeito ao inciso $\checkmark$ do art. 2 I 4 da CF: onde se diz que o Plano Nacional de Educação deve conduzir à promoção humanística, científica e tecnológica do País, muitas LOs não substituíram "País" por "Município", como seria o certo, uma vez que o Plano do Município só pode se referir ao Município. Algumas LOs distorceram o final do caput desse artigo, ao estabelecer que o Plano deve "introduzir" (LOs de Paracambi e Seropédica) ou "induzir" (LO de Itaboraí) a erradicação do analfabetismo, em lugar de "conduzir".

Outro exemplo de equívoco é o parágrafo Io do art. 27 I da LO de Itaguaí, cópia do parágrafo I o art. 212 da CF: "A parcela da arrecadação de 
impostos transferidos pela União ou pelo Estado ao Município não é considerada para efeito do cálculo previsto neste artigo". Obviamente, esta disposição só faz sentido na CF ou na $C E$, não em uma $L O$, pois a prefeitura não transfere recursos para outras esferas de governo.

A LO de Cabo Frio (parágrafo Io do art. 220) e a de Laje de Muriaé (parágrafo I do art. 138), por sua vez, estipulam que, para o cálculo dos recursos vinculados, "serão considerados os sistemas de ensino federais", o que é um triplo equívoco: primeiro, porque existe apenas um sistema de ensino federal; segundo, porque a LO não pode dispor sobre os recursos do sistema federal, mas apenas do municipal; terceiro, porque os recursos são vinculados à rede municipal, não ao sistema de ensino municipal, que é mais amplo, pois abrange também todas as escolas particulares de educação infantil localizadas no município. A LO de Vassouras (art. 173, parágrafo I -) comete equívoco semelhante ao prever que, no cálculo dos 25\% dos impostos vinculados à manutenção e ao desenvolvimento do ensino serão considerados os sistemas de ensino federal, estadual e municipal. A LO de São Gonçalo, por fim, refere-se aos sistemas de ensino municipal (art. 17I), quando existe apenas um.

Uma formulação muito comum nas LOs é a cópia do parágrafo 2ㅇ do art. 177 da Constituição Federal de 1967, imposta pela ditadura militar: "Cada sistema de ensino terá, obrigatoriamente, serviços de assistência educacional que assegurem aos alunos necessitados condições de eficiência escolar". Isso se deve, provavelmente, a ela ter sido incluída no "pacote" fornecido por uma consultoria ou por partido político.

Uma simples troca da conjunção "e" pela preposição "a" mudou totalmente o sentido do art. 210 da CF, que prevê "conteúdos mínimos para o ensino fundamental, de maneira a assegurar formação básica comum e respeito aos valores culturais e artísticos nacionais e regionais". Isso aconteceu pelo menos nas LOs de Cantagalo (art. 270) e Duque de Caxias (art. 97). Paracambi cometeu equívoco parecido ao prever, no parágrafo único do art. 149 , "o respeito, os valores culturais e artísticos locais", quando o certo seria "o respeito aos valores". Originalidade não faltou aos vereadores de Quatis que, ao copiarem o inciso II do art. 206: "liberdade de aprender, ensinar, pesquisar e divulgar o pensamento, a arte e o saber", substituíram "a arte e o saber" por "a arte do saber". 
Cópias incompletas ou com omissões foram feitas por várias LOs. A de Santo Antônio de Pádua (art. 162, parágrafo único) e outras suprimiram o trecho final do parágrafo I do art. 213 da CF: "ficando o Poder Público obrigado a investir prioritariamente na expansão de sua rede na localidade". A de São Fidélis subtraiu a pré-escola no inciso $\vee$ do art. 29, que ficou reduzido a manter "programas de educação de ensino fundamental". A de São João de Meriti esqueceu-se de indicar que a cooperação é com a União e o Estado no trecho: "manter, com cooperação técnica e financeira, programas de educação pré-escolar e de ensino fundamental" (inciso VI do art. 17).

A LO de Macaé é imprecisa no parágrafo 4으o art. 208, que prevê que os "programas suplementares de alimentação e assistência ao educando e à saúde, no ensino fundamental, serão financiados com recursos orçamentários". A assistência não é "à saúde", mas ao educando, e tais programas devem ser financiados com contribuições sociais (o salário-educação, por exemplo) e outros recursos orçamentários, o que significa que os $25 \%$ dos impostos destinados à educação não podem ser empregados com essa finalidade.

Na LO de São Francisco de Itabapoana, chama a atenção o art. I65, segundo o qual a educação tem como objetivo "o pleno desenvolvimento da pessoa sem preparo para o exercício da cidadania", onde a CF diz "e seu preparo".

Várias LOs se equivocaram na redação do artigo sobre a vinculação mínima de impostos para a educação. A de São Sebastião do Alto, por exemplo, prevê que o Município aplicará, anualmente, "nunca menos de $25 \%$ da receita resultante de impostos e das transferências recebidas do Estado e da União na manutenção e no desenvolvimento do ensino". Há duas imprecisões aqui: primeiro, não se ressalva que nem todas as transferências recebidas do Estado e da União são contabilizadas nos 25\% (por exemplo, os royalties de petróleo, o SUS); segundo, o texto não menciona especificamente impostos municipais, o que dá margem à interpretação de que não entram no cálculo.

No que se refere à destinação de recursos públicos para escolas comunitárias, confessionais ou filantrópicas, a maioria das LOs seguiu a formulação dos incisos I e II do art. 213 da CF ou do art. 3 I 5 parágrafo único da CE. A CF requer que essas escolas "comprovem finalidade não lucrativa, apliquem seus excedentes financeiros em educação e assegurem a destinação de seu patrimônio a outra escola comunitária, filantrópica ou confessional, ou ao 
Poder Público, no caso de encerramento de suas atividades”. A CE estipula que poderão receber até 3\% do percentual vinculado à educação "as escolas filantrópicas ou comunitárias comprovadamente sem fins lucrativos e que ofereçam ensino gratuito a todos que nelas estudam". Entretanto, pelo menos duas LOs infringem as normas constitucionais: a de Nova Iguaçu substituiu o termo "educação" por "escolas particulares" no texto da CF ("apliquem seus excedentes financeiros em educação"); e a de Bom Jardim autoriza que "escolas particulares não comunitárias, não confessionais ou não filantrópicas" recebam recursos públicos em forma de bolsas de estudo.

As LOs de Santa Maria Madalena e Trajano de Morais se confundiram nos números ao copiar o art. 60 do Ato das Disposições Constitucionais Transitórias da CF de 1988, que determina a vinculação por um período de dez anos de "pelo menos 50\% dos 25\%" da receita dos impostos para eliminar o analfabetismo e universalizar o ensino fundamental (no caso dos Estados e Municípios). Nessas LOs, fala-se de "pelo menos 25\% dos 25\%" (previstos no art. 2 I2), o que representa metade do valor estipulado pela Constituição.

\section{CÓPIAS EQUIVOCADAS DA CONSTITUIÇÃO ESTADUAL}

Um equívoco encontrado em todas as LOs, e que tem origem na CE, é a designação do ensino fundamental e do ensino médio como "I o grau" e "2oㅡ grau”, nomenclatura utilizada antes da Constituição Federal de 1988. Essa é uma falha imperdoável em legislação, pois pode levar o leitor desavisado a pensar que se trata de coisas distintas. Mais grave ainda é o uso da expressão "ensino primário", anterior à Lei 5.692 de 197 | que criou o ensino de I e 2ograus.

Outro equívoco, também originário da CE, é o emprego de "carga" em lugar de "grade" na seguinte formulação, reproduzida por dezenas de LOs: "nas escolas do 2ำ segmento do I grau far-se-á obrigatória a inclusão de atividade de iniciação e práticas profissionais nas oficinas objetivando promover o respeito dos valores e do primado do trabalho, tendo em vista as características socioeconômicas e culturais e a carga curricular oficial".

Entre os casos de cópias mal feitas da CE, mencione-se, por exemplo, a troca de "abastecimento alimentar" por "estabelecimento elementar" na transposição do caput do art. 254 ("a política agrícola dará prioridade à pequena produção e ao abastecimento alimentar, cabendo ao Poder Público instituir 
programa de ensino agrícola associado ao ensino não formal e à educação para preservação do meio ambiente"). O mesmo erro aparece nas LOs de Itaocara, Maricá, São Sebastião do Alto e Santa Maria Madalena.

Já as LOs de Areal, Comendador Levy Gasparian, Japeri e Mendes trocaram "formulação" por "formação" ao copiar a alínea a do inciso VI do art. 307 da CE, que prevê "a participação da sociedade na formulação da política educacional e no acompanhamento de sua execução" (o que seria interessante, mas nunca foi cumprido pelo governo do Rio de Janeiro e, provavelmente, nem pelos municípios que preveem essa participação). No mesmo trecho, a LO de São Francisco de Itabapoana troca o termo "execução" por "educação" (art. I66, inciso VIII). E a LO de Itaboraí reduziu o texto citado a "a participação de representantes de sua execução". Outro lapso da LO de Itaboraí está no art. 196 inciso XII, que prevê submeter os alunos matriculados na rede regular de ensino a "testes de desenvolvimento", quando o correto seria "testes de acuidade visual e auditiva, a fim de detectar possíveis desvios de desenvolvimento".

Algumas LOs erraram ao copiar a CE sem fazer as devidas adaptações para a esfera municipal. Por exemplo, o art. 169 da LO de Barra Mansa e o art. 197 da LO de Bom Jesus do Itabapoana se limitam a repetir o art. 315 da CE: "os recursos públicos estaduais destinados à educação serão dirigidos exclusivamente à rede pública de ensino" (no caso seriam recursos municipais). A LO de São João de Meriti prevê, no parágrafo único do art. 124, que o sistema municipal integrado de ensino será constituído pelos vários serviços educacionais desenvolvidos "no território fluminense", quando o certo seria "no município de São João de Meriti" ou, mais precisamente, "sob a jurisdição da Prefeitura de São João de Meriti”, uma vez que as escolas estaduais localizadas no município não integram o sistema municipal de ensino. Equívoco semelhante foi cometido pela LO de Mesquita.

As LOs de Iguaba Grande, Niterói, Rio de Janeiro e Valença se referem à "rede municipal mais próxima da residência", quando o certo seria "escola municipal", conforme o parágrafo 4 do inciso XIII do art. 308 da CE. O inciso I do art. 236 da LO de Niterói, por exemplo, estipula que o atendimento aos portadores de deficiência assegurará a matrícula em escola da rede municipal mais próxima de sua residência, em turmas comuns. 
Falhas elementares foram cometidas na transcrição do inciso $X I$ do art. 338 da CE, que prevê "oficinas abrigadas enquanto os portadores de deficiência não possam integrar-se ao mercado de trabalho competitivo". A LO de Quatis trocou “mercado" por "meio", enquanto a de Cachoeiras refere-se a "oficinas obrigatórias" e a de Três Rios a "oficinas obrigadas".

Clareza não foi o forte dos vereadores de Rio Claro na redação do parágrafo único do art. 179 da LO, que prevê que "os estabelecimentos de ensino público e privado deverão ser renovados, progressivamente, equipados materialmente e com recursos humanos qualificados", copiado erroneamente do parágrafo único do art. 327 da CE onde se lê: "Nos estabelecimentos de ensino público e privado deverão ser reservados espaços para a prática de atividades físicas, equipados materialmente e com recursos humanos qualificados".

artigo referente à assistência à saúde dos educandos, prevista na CE, e reproduzida em várias LOs, encontra às vezes formulações descabidas, o que faz crer que não são apenas os educandos que necessitam dessa assistência, mas também os vereadores, pelo menos a oftalmológica e/ou redacional. Veja-se o caso de Mendes: o art. 170 da LO do município prevê "assistência à saúde dos educandos, no que se refere ao tratamento médico-odontológico ou destes decorrentes, independente da idade dos educandos" - o que não faz sentido. O correto seria, conforme o texto original da CE: "tratamento médico-odontológico e atendimento aos portadores de problemas psicológicos ou destes decorrentes".

\section{ERROS E FORMULAÇÕES PROVAVELMENTE COPIADAS DE MODELOS FORNECIDOS POR CONSULTORIAS OU PARTIDOS POLÍTICOS}

Vários erros e formulações comuns a muitas LOs indicam que, como não constavam da CF e da CE, foram provavelmente copiados de modelos fornecidos por consultorias legislativas ou partidos políticos. Minha hipótese baseia-se no fato de que um mesmo erro ou uma mesma formulação não constante da CF e da CE não se repetiria por acaso em tantas LOs. A seguir apresento alguns deles. 


\section{QUADRO I \\ ERROS COMUNS A MUITAS LOS}

I) Uso de "compreendida e" em vez de "compreendida a"

Muitas LOs - por exemplo, as de Bom Jesus do Itabapoana, Cantagalo, Laje de Muriaé, Mendes, Natividade, Paraíba do Sul, Paraty, Quatis, Rio das Ostras, São João de Meriti - estipularam que o município aplicaria, anualmente, nunca menos de $25 \%$ da receita resultante de impostos, compreendida e proveniente de transferências, na manutenção e desenvolvimento do ensino, quando o certo seria "compreendida a".

2) Repetição de duas expressões com o mesmo sentido: "Nunca menos ... no mínimo", quando o certo seria usar uma ou outra. Um exemplo é a LO de Itaguaí, que, no art. 27I, estipula que "o Município aplicará, anualmente, nunca menos de 25\%, no mínimo da receita resultante de impostos, compreendida a proveniente de transferências, na manutenção e desenvolvimento do ensino". $\bigcirc$ mesmo equívoco consta das LOs de Nova Friburgo, Rio das Flores, São Fidélis, Trajano de Morais e Valença e muitas outras.

3) Uso errado do sujeito na formulação: "O ensino do Município atuará prioritariamente no préescolar e no ensino fundamental". O certo é: "O município atuará ...". Esse equívoco é encontrado nas LOs de Cantagalo, Casimiro, Miracema, Natividade, Nova Iguaçu, Paraíba do Sul, Paraty, Quatis, São Pedro da Aldeia, Silva Jardim, Valença, Varre-Sai e outras.

4) "Compete ao Município manter, privativamente, com a cooperação técnica e financeira da União e do Estado, programas de educação pré-escolar e de ensino fundamental". O equívoco é a inclusão de "privativamente" (não previsto na CF e na CE), que dá a entender que só os Municípios podem manter tais programas. Ele se repete em 13 LOs: de Campos, Carmo, Comendador Levy Gasparian, Laje de Muriaé, Macaé, Maricá, Petrópolis, Rio Claro, Rio das Flores, Santa Maria Madalena, São Fidélis, Saquarema e Três Rios.

5) Uso de "princípios" em lugar de "dever" ou "garantia de". Um exemplo é o art. I 83 da LO de Areal, segundo o qual o ensino seria ministrado com base nos seguintes princípios: "VI - implantação de programas suplementares de alimentação, assistência à saúde e material didático escolar; VII implantação de Sistema de passagem escolar, nos ônibus, para os alunos da rede oficial do Município; VIII - oferta de ensino noturno regular, adequado às condições do educando". Ora, tais incisos não são princípios. Equívocos semelhantes encontram-se nas LOs de Cordeiro, Comendador Levy Gasparian, Mendes, Natividade, Porciúncula e Vassouras.

6) Os vereadores de alguns municípios (Duas Barras, Miguel Pereira, Natividade, Quatis, Rio Claro, São Fidélis, Valença) parecem ter dificuldade com a consoante "d" em palavras que não sejam oxítonas, pois trocam "mandado" por "mandato" na elaboração das LOs.

\section{QUADRO 2}

\section{FORMULAÇÕES COMUNS A MUITAS LOS NÃO CONSTANTES DA CF E DA CE}

I) "O sistema de ensino municipal assegurará aos alunos necessitados condições de eficiência escolar". Essa formulação tem a particularidade de ser copiada do parágrafo 2o do art. 177 da CF de 1967 , segundo o qual "Cada sistema de ensino terá, obrigatoriamente, serviços de assistência educacional que assegurem aos alunos necessitados condições de eficiência escolar". 
(continuação)

2) "O Município manterá o professorado municipal em nível econômico, social e moral à altura de suas funções". Formulação vaga e inócua encontrada em dezenas de LOs. Certamente, o professorado não foi nem é mantido em nível econômico (salários) à altura de suas funções. Não comentamos as expressões "nível social e moral" porque são muito vagas. Algumas poucas LOs procuram ser mais concretas, como a de Tanguá, que acrescenta, depois de "funções": "garantindo-lhe vencimentos no mínimo equivalentes aos de outras funções do âmbito municipal que exijam formação em grau semelhante".

3) "O calendário escolar municipal será flexível e adequado às peculiaridades climáticas e às condições sociais e econômicas dos alunos".

4) "Os currículos escolares serão adequados às peculiaridades do Município e valorizarão sua cultura e seu patrimônio histórico artístico, cultural e ambiental".

5) "Compete ao prefeito providenciar sobre o incremento do ensino". Formulação vaga e inócua.

6) "O Município promoverá formação de consciência sanitária individual nas primeiras idades, através do ensino primário". O autor esqueceu que a nomenclatura "ensino primário" deixou de existir em 1971, a partir da Lei 5.691, que criou o Io e o 20 graus.

7) "A inspeção médica nos estabelecimentos de ensino municipal terá caráter obrigatório".

8) "O Município auxiliará, pelos meios ao seu alcance, as organizações beneficentes, culturais e amadoristas, nos termos da lei, sendo que as amadoristas e as colegiais terão prioridade no uso dos estádios, campos e instalações de prioridade do Município".

9) "O Município orientará e estimulará, por todos os meios, a educação física, que será obrigatória nos estabelecimentos municipais de ensino e nos particulares que recebem auxílio do Município". Segundo Catani e Oliveira (1993), essa formulação constaria de algumas LOs paulistas, o que indica que o mesmo modelo de consultoria foi vendido para outros estados.

I0) "O Município constituir-se-á em agente socializador na formação da identidade cultural das novas gerações através da integração Educação/Cultura".

I I) "O Município manterá obrigatoriamente em todas as escolas municipais que proporcionem ensino a partir da 5a série uma biblioteca. Parágrafo Único - Toda escola que vier a ser construída pelo Município a partir da promulgação desta Lei Orgânica terá obrigatoriamente uma área destinada à biblioteca, independente do nível de ensino oferecido". As LOs de Araruama, Búzios, Cabo Frio, Carapebus, Iguaba Grande, Itaboraí, Niterói, Quissamã, Rio de Janeiro, São Francisco de Itabapoana têm formulação idêntica ou parecida.

12) "O Município deve manter e promover permanente adequação dos conteúdos dos currículos escolares da comunidade relacionados econômica e socialmente à pesca, a sua vivência, realidade e potencialidade pesqueira" (art. 264, inciso II da LO de Rio das Ostras). Formulação idêntica ou bastante semelhante é encontrada em várias LOs, como as de Arraial do Cabo, Quissamã, Niterói, Macaé, Cabo Frio e Cardoso Moreira, São Francisco de Itabapoana, Saquarema e São João da Barra.

13) "O Município fomentará as práticas desportivas, especialmente nas escolas a ele pertencentes".

14) "O órgão municipal de educação será dirigido por profissional de educação, cabendo-lhe a administração da política educacional do Município".

15) "A Secretaria Municipal de Educação publicará anualmente relatórios globalizando o trabalho realizado, bem como os resultados obtidos". 
(continuação)

16) "Eleição direta para o Corpo Administrativo com a participação da Comunidade Escolar". (art. I79 da LO de Casimiro de Abreu). Poucas LOs fazem referência ao "corpo administrativo", como Cardoso Moreira, Macaé, o que é muito peculiar, pois esse corpo inclui funcionários administrativos quando as eleições são apenas para a direção da escola.

17) "O ano letivo na rede municipal de ensino público terá, no mínimo, a duração fixada na legislação federal. Não serão considerados dias letivos do período mínimo a que tem direito o aluno aqueles em que não houver aula para a turma em que ele estiver matriculado". Poucas LOs têm essa formulação, contida na LO do Rio de Janeiro e copiada pelas LOs de Búzios, Carapebus e Guapimirim, que se emanciparam depois de 1990.

18) "As despesas provenientes da cessão de material ou de pessoal da Secretaria Municipal de Educação a outros setores da administração municipal não serão consideradas recursos destinados à manutenção e desenvolvimento do ensino público municipal previstos no caput deste artigo".

\section{CONTRIBUIÇÕES “ORIGINAIS”: ERROS E CONTRADIÇÕES}

Além de cópias incorretas da CF, CE ou até de modelos fornecidos por consultorias ou partidos políticos, os vereadores contribuíram com equívocos originais para suas LOs (Quadro 3). Somam-se aos erros, várias contradições internas. A LO de Piraí, por exemplo, estipula que compete ao município manter, sempre que possível, ensino de $2 \circ$ grau e superior (art. 9, inciso VII), contrária ao parágrafo 3으o do art. 205 da LO, que veda a ampliação de sua oferta em níveis ulteriores de ensino, enquanto não atendida plenamente a demanda nos "níveis iniciais". A LO de Cardoso Moreira prevê, no art. 200, que o município não manterá escolas de 2 grau até que estejam atendidas todas as crianças de idade de até 14 anos, bem como não manterá nem subvencionará estabelecimentos de ensino superior. Entretanto, no art. 204, assegura ao servidor público, ativo ou inativo, bem como a seus filhos, bolsas de estudo integrais em cursos de nível superior, o que é uma forma de subvenção a estabelecimentos de ensino superior.

QUADRO 3

ERROS INTRODUZIDOS PELOS VEREADORES

\begin{tabular}{|l|l|}
\hline \multicolumn{1}{|c|}{ LO } & \multicolumn{1}{c|}{ Erro } \\
\hline Cabo Frio & $\begin{array}{l}\text { Os vereadores fixaram um percentual de algo que é apenas potencial, não real, } \\
\text { no parágrafo 3 do art. 220: "5\% do potencial referido neste parágrafo serão } \\
\text { destinados especificamente à educação especial". }\end{array}$ \\
\hline $\begin{array}{l}\text { Cachoeiras de } \\
\text { Macacu }\end{array}$ & $\begin{array}{l}\text { Previram que a gratuidade do ensino será prioritária (inciso I do art. 295), quando } \\
\text { ela é obrigação da prefeitura. }\end{array}$ \\
\hline
\end{tabular}

(continua) 
(continuação)

\begin{tabular}{|c|c|}
\hline $\begin{array}{l}\text { Engenheiro Paulo } \\
\text { de Frontin }\end{array}$ & $\begin{array}{l}\text { Não procederam corretamente no uso de "procedente" no art. 238: "São } \\
\text { isentos de tarifas, nos serviços de transportes coletivos municipais, mediante } \\
\text { a apresentação de documento de passe livre, a ser instituído pelo poder } \\
\text { procedente". O certo é "concedente". }\end{array}$ \\
\hline Itaocara & $\begin{array}{l}\text { O seu plano de educação pretendeu "erradicar o alfabetismo", o que resultaria, } \\
\text { se bem-sucedido, na universalização do analfabetismo! }\end{array}$ \\
\hline Laje de Muriaé & $\begin{array}{l}\text { Parecem acreditar que o racismo será eliminado simplesmente suprimindo-se } \\
\text { a palavra da LO. Foi o que fizeram ao substituí-la por "regime" no art. I33, que } \\
\text { prevê a "eliminação da todas as formas de regime e discriminação". }\end{array}$ \\
\hline Macaé & $\begin{array}{l}\text { Cunharam a expressão "padrões comportáveis da sociedade" (art. I 87), quando } \\
\text { provavelmente quiseram dizer "comportamentais", como nas LOs de Cordeiro, } \\
\text { Santa Maria Madalena e Três Rios. }\end{array}$ \\
\hline Macuco & $\begin{array}{l}\text { Embora cursos precisem de recursos, estas duas palavras não devem ser } \\
\text { confundidas, como aconteceu com o parágrafo } 3 \text { 이 do art. 224: "O Município } \\
\text { facilitará a implantação de recursos técnicos e profissionalizantes". }\end{array}$ \\
\hline Magé & $\begin{array}{l}\text { Introduziram, com a Emenda n. I3, de I3/8/97, o pré-escolar no ensino } \\
\text { fundamental, no inciso I do art. I85, que passou a ter a seguinte formulação } \\
\text { equivocada: "ensino fundamental obrigatório do Pré-escolar a 8ª série". }\end{array}$ \\
\hline Mangaratiba & $\begin{array}{l}\text { Transformaram "instituições" em "instalações" no inciso XII do art. 287: "eleições } \\
\text { diretas [...] para direção das instalações de ensino mantidas pelo Poder Público, } \\
\text { com a participação da comunidade escolar". }\end{array}$ \\
\hline Natividade & $\begin{array}{l}\text { Referem-se (art. I7I) ao desenvolvimento infantil nos "espaços socioafetivos, } \\
\text { linguísticos", quando o certo é "aspectos", não "espaços". A LO de Porciúncula } \\
\text { cometeu erro idêntico. Quem copiou de quem? }\end{array}$ \\
\hline Nilópolis & $\begin{array}{l}\text { Cometeram vários equívocos no parágrafo Iㅇ do art. I58, que prevê que a "União } \\
\text { prestará assistência técnica e financeira ao Município para o desenvolvimento de } \\
\text { seus sistemas de ensino e atendimento prioritário à escolaridade". O primeiro } \\
\text { é que não cabe a uma Lei Orgânica estipular que a União prestará assistência } \\
\text { ao município. O segundo é que o município só tem um sistema de ensino, não } \\
\text { "sistemas de ensino". O terceiro é que não define a escolaridade. }\end{array}$ \\
\hline Niterói & $\begin{array}{l}\text { Em Niterói, Paracambi e Seropédica usaram "consonância" em vez de } \\
\text { "colaboração". A LO de Niterói, por exemplo, prevê "a) provimento dos } \\
\text { cargos de Diretores e Diretores Adjuntos das instituições educacionais [...] por } \\
\text { eleições diretas, com a participação da comunidade escolar, conforme normas } \\
\text { estabelecidas pela Secretaria Municipal de Educação, em consonância com as } \\
\text { entidades representativas dos segmentos integrantes da referida comunidade" } \\
\text { (inciso V do art. 219). }\end{array}$ \\
\hline Paracambi & $\begin{array}{l}\text { No trecho: "Recensear periodicamente as crianças em idade escolar, com a } \\
\text { finalidade de orientar a política de expansão da rede pública municipal e superar } \\
\text { a demanda de novas matrículas", obviamente, o objetivo edílico era o verbo } \\
\text { "suprir", e não "superar". Além disso, tal como os vereadores de Niterói, usaram } \\
\text { "consonância" em lugar de "colaboração" no parágrafo único do art. I 42: "Caberá } \\
\text { ao Município, em consonância com o Estado e a União ....". }\end{array}$ \\
\hline
\end{tabular}


(continuação)

\begin{tabular}{|c|c|}
\hline Paraíba do Sul & $\begin{array}{l}\text { Empregaram "conveniência" em vez de "convivência" no seu art. I65: "A } \\
\text { educação, [...] visando o pleno desenvolvimento da pessoa, [...] qualificação } \\
\text { para o trabalho e conveniência solidária a serviço de uma sociedade justa, fraterna, } \\
\text { livre e soberana". A CF prevê "convivência". }\end{array}$ \\
\hline Paraty & $\begin{array}{l}\text { A difusão do saber médico a toda a população é prevista no inciso II do art. I } 60 \\
\text { da LO: "progressiva extensão obrigatoriedade e gratuidade do ensino médico". }\end{array}$ \\
\hline Quatis & $\begin{array}{l}\text { Confundiram "locação" com "alocação", como no inciso Il do art. 200: "com o } \\
\text { objetivo de acompanhar e fiscalizar a locação de recursos e o nível pedagógico } \\
\text { da escola". }\end{array}$ \\
\hline Rio Bonito & $\begin{array}{l}\text { Transformaram "anteprojeto" em "antiprojeto" (parágrafo único do art. I06). } \\
\text { O art. 99, transcrito a seguir, ao omitir a vírgula depois de "cidadãos", mudou } \\
\text { totalmente o sentido, que passou a ser o de que o direito é só dos cidadãos } \\
\text { sem preconceito, o que não deixa de ser um preconceito: "O ensino público, é } \\
\text { direito de todos os cidadãos sem preconceito de origem, raça sexo, cor, idade, } \\
\text { classe social, preferências políticas ou qualquer outras formas de discriminação". }\end{array}$ \\
\hline Rio Claro & $\begin{array}{l}\text { Confundiram "repasse" com 'passe' e não primaram pela clareza no art. } 209 \text { da } \\
\text { LO, segundo o qual o Município teria a obrigação de "prover de repasse escolar, } \\
\text { nos transportes coletivos municipais, o ensino fundamental de sua competência". } \\
\text { Uma formulação mais apropriada seria: "É obrigação do Município fornecer passe } \\
\text { aos alunos das escolas municipais de ensino fundamental para uso em transportes } \\
\text { coletivos municipais". }\end{array}$ \\
\hline Rio das Flores & $\begin{array}{l}\text { Criaram uma nova categoria de escolas, as "confeccionais", em lugar de } \\
\text { "confessionais". }\end{array}$ \\
\hline $\begin{array}{l}\text { Santa Maria } \\
\text { Madalena }\end{array}$ & $\begin{array}{l}\text { Mudaram o sentido ao usar "peçam" em vez de "impeçam" no parágrafo I do } \\
\text { art. 389: "Incentivar e fiscalizar a frequência às aulas adotando medidas que } \\
\text { peçam a evasão escolar"'. Não souberam copiar a CF no inciso XIX do art. } 49 \\
\text { ao omitir a vírgula depois de "exceto" e usar "incompatibilidade" em vez de } \\
\text { "compatibilidade": "é vedada a acumulação remunerada de cargos públicos, } \\
\text { exceto quando houver incompatibilidade de horário". }\end{array}$ \\
\hline São Fidélis & $\begin{array}{l}\text { Empregaram "selar" em lugar de "zelar" no artigo que estipula que o Poder } \\
\text { Público deve zelar, junto aos pais ou responsáveis, pela frequência à escola, } \\
\text { e empregaram "sede" em lugar de "rede" no artigo que obriga o Município a } \\
\text { investir na expansão de sua rede na localidade. }\end{array}$ \\
\hline São João da Barra & $\begin{array}{l}\text { Não souberam copiar o modelo fornecido por consultoria ou partido político } \\
\text { ao omitir "com" depois de "socialmente" e mencionar "vigência" em vez de } \\
\text { "vivência" no art. 233, que prevê "adequação dos conteúdos dos currículos } \\
\text { escolares das comunidades envolvidas econômica e socialmente a pesca, à sua } \\
\text { vigência, realidade e potencialidade pesqueira". }\end{array}$ \\
\hline $\begin{array}{l}\text { São João de } \\
\text { Meriti }\end{array}$ & $\begin{array}{l}\text { Várias LOs dão mais privilégios às escolas privadas do que as permitidas pela } \\
\text { CF ou CE. Uma delas é a de São João de Meriti, que confundiu "obrigação" } \\
\text { com "isenção" no parágrafo único do art. I29: "O valor das bolsas de estudos } \\
\text { a que se refere este artigo poderá ser compensado com obrigação fiscal do } \\
\text { estabelecimento de ensino". }\end{array}$ \\
\hline
\end{tabular}

(continua) 
(continuação)

\begin{tabular}{|l|l|}
\hline Sapucaia & $\begin{array}{l}\text { Criaram um novo nível de ensino (o ensino fundamental de primeiro grau!) no } \\
\text { parágrafo 2o- do art. } 7^{\circ} \text { da Lei Orgânica: "A História do Município deverá ser incluída } \\
\text { no currículo escolar municipal para o ensino fundamental de primeiro grau". }\end{array}$ \\
\hline Seropédica & $\begin{array}{l}\text { Confundiram-se ao supor que primeiro grau é diferente de ensino fundamental, } \\
\text { no item e do art. I 38: "e) educação ambiental, entre outras matérias, no currículo } \\
\text { escolar do ensino pré-escolar, fundamental, do Io e 2o graus e profissionalizante". } \\
\text { Devem pensar que "consonância" significa o mesmo que "colaboração", pois o } \\
\text { parágrafo único do art. I } 40 \text { prevê o Município, "em consonância com o Estado } \\
\text { e a União..." Erro idêntico ao da LO de Paracambi. }\end{array}$ \\
\hline Varre-Sai & $\begin{array}{l}\text { Empregaram "ressenceamento" em vez de "recenseamento", "estipulará" em } \\
\text { vez de "estimulará" e "estimação precoce" em vez de "estimulação". A mesma } \\
\text { LO classificou ilegalmente as despesas com merenda como manutenção e } \\
\text { desenvolvimento do ensino (art. 235). }\end{array}$ \\
\hline
\end{tabular}

Essa ilegalidade (despesas no ensino superior) é cometida por várias outras LOs. Umas na forma de concessão de bolsas, como Araruama (art. 165), Campos (art. 55 das Disposições Transitórias), Casimiro de Abreu (art. 186), Macaé (art. 205), Porto Real (art. 199), Rio das Ostras (art. 196) e Santa Maria Madalena (art. 405). Outra (Angra dos Reis), na forma de cessão de terreno ou prédio para a implantação de ensino superior (art. 245).

Já a LO de Itaboraí prevê (art. 205 e 206) gasto com a Fundação Educacional Itaboraí, com dotação de $0,5 \%$ do orçamento. Situação parecida existe em Nova Friburgo, onde a prefeitura mantém uma faculdade de odontologia. Em Macaé, a LO garante um percentual para uma fundação privada, a Fundação Educacional Luiz Reid, sendo 50\% destinados a abater o valor das mensalidades cobradas aos alunos (art. 208). As LOs de Itaguaí (art. 245) e Itaperuna preveem a criação de uma fundação de ensino superior. A LO de Itaocara atribui à prefeitura a tarefa de facilitar a instalação do curso de agronomia previsto no parágrafo I o do art. 49 da Disposições Transitórias da CE.

Por sua vez, as LOs de Mangaratiba (art. 322), Paraty (art. 160), Porto Real (art. 199) e Teresópolis (art. 176, inciso VI) financiam o transporte de estudantes universitários. Tal gasto municipal no ensino superior seria ilegal porque a CF de 1988 determinou que a atuação prioritária dos municípios seria na educação pré-escolar (ampliada para educação infantil pela Emenda Constitucional 14, em 1996) e no ensino fundamental, e porque a LDB determinou que as prefeituras só poderiam atuar em níveis ulteriores ao ensino 
fundamental, ou seja, no ensino médio e no superior, depois de atendida a demanda por educação infantil e ensino fundamental.

A contradição também está presente na LO de Tanguá. $\bigcirc$ art. 223 autoriza a privatização de modo bem amplo, ao permitir que a prefeitura faça convênios com empresas, entidades religiosas ou particulares e pessoas físicas para "atender a obrigação de garantia do ensino fundamental obrigatório e gratuito". Porém, o parágrafo único restringe a destinação de verbas públicas para o ensino particular à concessão de bolsas. Já o art. 224 faz várias outras restrições: os recursos públicos só podem ser dirigidos a escolas comunitárias, confessionais ou filantrópicas que não cobrem pagamento pelos serviços educacionais prestados e assegurem a destinação de seu patrimônio a outra escola comunitária, confessional ou filantrópica ou ao Município, no caso de encerramento de suas atividades. É interessante que a mesma redação do art. 223 de Tanguá seja encontrada nas LOs de Japeri, Queimados e Petrópolis. Visto que as três primeiras são posteriores a 1990, é provável que o texto tenha sido copiado da LO de Petrópolis, que as precedeu.

Outra contradição de várias LOs é prever a exclusividade de recursos públicos para escolas públicas e, ao mesmo tempo, permitir ou prever que uma parte do percentual mínimo dos impostos poderá ou será destinado a escolas comunitárias, confessionais ou filantrópicas. Algumas poucas (Santo Antônio de Pádua, Miracema, Quissamã) chegam a reservar uma parte do percentual para escolas cenecistas (Campanha Nacional das Escolas da Comunidade). É verdade que tal contradição tem origem na formulação equivocada do art. 3 I 5 parágrafo único da CE, que prevê essa exclusividade, mas permite que até $3 \%$ do percentual mínimo da CE se destine a essas escolas, desde que sejam comprovadamente sem fins lucrativos e ofereçam ensino gratuito a todos que nelas estudam - condições nem sempre seguidas pelos vereadores. Mais adiante, comento as diferenças na redação desse item nas LOs.

Uma contradição comum, encontrada, por exemplo, nas LOs de Angra dos Reis, Arraial do Cabo, Cachoeiras, Bom Jardim, Comendador Levy Gasparian e Duque de Caxias, é a previsão de o Município oferecer creches e pré-escolas e, ao mesmo tempo, incentivar empresas a manter as creches dos filhos de seus funcionários. 


\section{CONTRIBUIÇÕES ORIGINAIS SEM ERROS}

A maioria das LOs é apenas uma colcha de retalhos da CF, da CE e de modelos fornecidos por consultorias ou partidos políticos, porém, contém uma ou outra contribuição própria dos vereadores ou dos eleitores e de suas entidades, os quais supostamente representam. O grau de originalidade varia muito entre as LOs. Poucas são bastante originais, ou seja, contêm muitos artigos incomuns, como as de Arraial, Barra Mansa, Carmo, Rio de Janeiro e Volta Redonda. A relação a seguir não pretende ser exaustiva de contribuições originais.

A "sensibilidade" social do discurso dos vereadores está presente na LO de São Gonçalo, que prevê a construção anual de no mínimo duas escolas para ensino de "primeiro grau" nos bairros mais distantes e carentes, dever não cumprido pela prefeitura até hoje, mais de 20 anos depois da promulgação da LO. Outra contribuição é o privilégio à mão de obra dos munícipes em obras e serviços realizados nas escolas, como é o caso das LOs de São João da Barra e de São Francisco de Itabapoana (este se desmembrou daquele), cujo art. 28 obriga a prefeitura a empregar profissionais do município para a confecção de carteiras escolares e a construção de escolas, desde que "os preços sejam economicamente viáveis e não haja problema de qualidade".

Provavelmente com o objetivo de impedir ou pelo menos dificultar fraudes em obras nas escolas, a LO do Rio de Janeiro é a única a prever (art. 17I) que o diretor da escola integrará a comissão de aceitação definitiva ou provisória das obras e serviços de reformas, ampliação, manutenção ou conservação da escola onde se realiza a obra ou serviço.

Embora a gratuidade seja um dos princípios declarados da educação pública, nada garante que seja cumprida pelos governos ou funcionários das escolas, como sugere a LO de Rio Bonito, a única que proíbe expressamente (art. 104) "a cobrança ou aceitação graciosa de todo e qualquer material escolar ou taxas aos pais e/ou responsáveis pelos estudantes, como condição que esses se matriculem em qualquer escola pública municipal".

A de São Pedro da Aldeia é a única também a prever que a atividade escolar "desenvolverá estudo, pesquisa e experiência, objetivando, tanto quanto possível, adequar a prática à teoria” (parágrafo 2ㅇo do art. 176) e a habilitação de professores para atuação específica na área rural, adequando a escola às necessidades locais (parágrafo 4ㅇ do art. 176). 
Uma definição menos genérica do princípio do padrão de qualidade aparece em algumas poucas LOs, uma delas a de Duque de Caxias, que prevê: a) convênios de assessoria do magistério municipal com as universidades públicas localizadas no Estado do Rio de Janeiro; b) intercâmbio com as associações de classe e as entidades de pesquisa do Estado; c) instalação de salas de leitura, salas de arte, quadra de esportes, teatro e/ou auditório em todas as unidades escolares; d) livros de atualização para os professores. A de Carmo prevê vários itens, um deles raro: a avaliação cooperativa periódica por órgão próprio do sistema educacional, pelo corpo docente, pelos alunos e pelos responsáveis. Aliás, essa é a única ou uma das poucas LOs a prever programas de material didático-escolar, transporte, alimentação e assistência à saúde também em creches e pré-escolas, não apenas no ensino fundamental, como previsto na CF, na CE e na maioria das LOs.

Com relação ao ensino religioso, a maioria das LOs reproduz o que prevê a CF, porém, algumas inovam. A de Magé (art. 175), por exemplo, estabelece que esse ensino será sem ônus para a prefeitura. É o caso também da LO de Araruama, que estipula (art. 163, parágrafo lo) que ele será oferecido segundo as opções confessionais manifestadas por grupos que representem pelo menos um quinto do alunado da classe, e ministrado por orientadores religiosos designados pelas respectivas instituições, assegurando-se atividades alternativas para os demais alunos. As de Itaboraí (art. 200) e de Arraial do Cabo (art. 221, parágrafol ㅇ) preveem algo similar e, o que é raro, que os alunos e seus responsáveis serão informados do caráter facultativo da matrícula no ensino religioso e das atividades alternativas a esse ensino. As de Angra (art. 250) e Paraty (art. 162, parágrafo 3을 são as únicas a atribuírem ao ensino religioso a função de fazer a inimaginável síntese entre ciência, cultura e fé. A participação ou interferência de autoridades religiosas no credenciamento de professores não é comum e está prevista em várias LOs, como as de Cambuci e São José de Ubá.

Na questão do livro didático, a LO de Campos inova ao estabelecer: "A linha de livros adotada para cada série, no ensino municipal de primeiro e segundo graus, de comum acordo entre o professorado e a supervisão, com o referendo do titular da Secretaria Municipal de Educação, terá validade por três anos subsequentes, ficando abolido o caderno de atividades". (art. 219). A preocupação com a duração do material didático é demonstrada por outras 
LOs: a de Petrópolis define que seja usado por um período mínimo de quatro anos (art. 148, parágrafo 2o); a de Carmo determina a adoção de livros didáticos não consumíveis e o reaproveitamento deles (art. 207). e a de Belford Roxo (art. 172 parágrafo $2^{\circ}$ ) prevê que eles tenham a validade mínima de três anos.

Raríssima é a preocupação com a alfabetização do idoso, só constando das LOs de Búzios e Carapebus.

Os vereadores de Saquarema foram os únicos a demonstrar sensibilidade com a escolarização de trabalhadores ao obrigar as empresas a reduzir a jornada em até duas horas, sem prejuízo salarial, para esse fim. No entanto, dois anos depois de promulgada a LO, essa sensibilidade desapareceu, com a revogação do inciso do art. 173 que previa isso.

Quanto à valorização dos profissionais da educação, a maioria das LOs copiou a CF, mas algumas introduziram aspectos novos. A de Niterói (art. 219) prevê que o piso salarial nunca seja inferior ao do Estado, na suposição de que este seja digno de referência positiva, o que foi desmentido nos últimos 20 anos, quando a remuneração de muitos municípios superou a do Estado. A de Sumidouro demonstra preocupação semelhante. Pelo menos duas LOs tratam da lotação do profissional da educação. A de Barra Mansa prevê, no art. 33 das Disposições Transitórias, que o Município cuidará para que ele seja lotado nas escolas mais próximas de sua residência. A de Macuco (art. 229) estipula que o professor escolherá as turmas e as escolas com base no seu tempo de serviço e habilitação específica. Quanto ao direito de greve dos professores, a LO de São Pedro da Aldeia é a única que prevê o direito dos educandos de receberem, durante o período em que durar a paralisação, todo o material didático e apostilas correspondentes às matérias e as aulas que deixarem de ser ministradas (art. 12 das Disposições Gerais e Transitórias).

A sensibilidade para a relação entre educação e cultura só é manifestada na LO de Nova Iguaçu e seguida por Belford Roxo, depois de seu desmembramento na década de 1990. Essa relação seria promovida por agentes de cultura que exerceriam várias funções de integração com a escola, sem se confundirem com o professor de educação artística (art. 172 e 173). Essas duas LOs e a de Japeri (também desmembrada de Nova Iguaçu) contêm um artigo encontrado apenas nelas, que prevê a "inclusão no ensino médio de conteúdo sobre as lutas das mulheres, resgatando a história da mulher na sociedade" - inclusão 
dificilmente cumprida pelo simples fato de a prefeitura não ser obrigada a atuar no ensino médio.

Várias LOs copiaram a CE ao prever o estabelecimento progressivo do turno único, mas a de Miguel Pereira foi uma das raras a estipular um prazo (cinco anos) para a ampliação da carga horária para oito horas diárias, ou 40 horas semanais. No entanto, ao que parece, esse prazo não chegou a ser cumprido.

$\bigcirc$ risco de submissão da entidade de estudantes aos interesses do prefeito está implícito no art. I 59 da LO de Petrópolis, que prevê subvenção da prefeitura à Associação Petropolitana de Estudantes, que poderia se tornar, com isso, mera correia de transmissão dos interesses do alcaide, como tem acontecido com muitas entidades estudantis.

Na determinação do percentual mínimo dos impostos, a criatividade e sensibilidade edílicas em alguns municípios fixaram, muito provavelmente por pressão e/ou influência de entidades educacionais, sobretudo sindicatos de professores, percentuais maiores do que os $25 \%$ estabelecidos pela CF. Entretanto, este idílio desapareceu ao longo da década de 1990, e os percentuais foram reduzidos para o mínimo de $25 \%$, por motivo que, certamente, não foi o atendimento pleno e satisfatório das necessidades educacionais da população dos municípios em questão.

Previam percentuais maiores, na sua origem, depois diminuídos para 25\%, as LOs de Casimiro (30\%), Cabo Frio (35\%), Itaocara (30\%), Itaperuna (28\%), Macaé (35\%), Magé (30\%), Mangaratiba (35\%), Petrópolis (35\%), São Gonçalo (35\%), São Pedro da Aldeia (35\%) e Saquarema (30\%). Em Duque de Caxias, o percentual inicial foi alterado de "pelo menos 35\%" para "até $35 \%$ ", o que, em tese, permite ao prefeito aplicar qualquer percentual inferior a 35\% - uma formulação inédita para a vinculação de impostos para a educação. A propósito do "pelo menos", a LO de Niterói foi bastante parcimoniosa, sendo a única a omitir tal expressão. $O$ prefeito do Rio de Janeiro chegou a recorrer à Justiça, alegando a inconstitucionalidade dos 35\% estipulados pela LO, e depois de conseguir uma liminar favorável, em julho de 1999, passou considerar apenas os $25 \%$ da CF. Entre as poucas LOs que mantiveram percentuais mínimos maiores que 25\% estão as de Arraial (30\%), Barra Mansa (30\%), Cachoeiras de Macacu (35\%), Maricá (30\%), Porto Real (30\%), Quatis (30\%), Resende (35\%), Volta Redonda (30\%) e Teresópolis (30\%). 
Algumas LOs se inspiraram no parágrafo único do art. 3 I 5 da CE, que prevê a possibilidade de destinação de até 3\% do percentual mínimo para escolas filantrópicas ou comunitárias comprovadamente sem fins lucrativos e que ofereçam ensino gratuito a todos que nelas estudam. É o caso de Cantagalo, Itaocara, Maricá, Mangaratiba, Mendes, Paraty, Piraí, São João de Meriti e Três Rios, com a diferença de que Cantagalo fixou um percentual máximo maior (6\%) e Piraí, um menor (2\%). A de Maricá reduziu, em 1992, o percentual para $2 \%$, mas mantendo a inconstitucionalidade de destinar tais recursos para entidades esportivas.

As LOs de Bom Jardim, Cordeiro, Macuco, Magé, Quissamã e Santa Maria Madalena foram além, ao tornar obrigatória, e não mais opcional, a destinação de recursos públicos para escolas confessionais, filantrópicas e comunitárias. Por exemplo, LO de Cordeiro (seguida por Macuco, depois de seu desmembramento) prevê que 30\% do percentual mínimo (27\%) dos impostos vinculados à educação, ou seja, 8, I \%, "serão aplicados" conforme o art. 213 da CF, a saber, nessas escolas. O mesmo fizeram as LOs de Bom Jardim, Magé e Santa Maria Madalena, embora o percentual ( $10 \%)$ não seja tão generoso quanto o de Cordeiro e Macuco (30\%), o que significaria 3\% em Magé (antes de o percentual mínimo ser reduzido de 30\% para 25\%), 3,5\% em Bom Jardim (cuja LO estipula o percentual mínimo de 35\%) e 2,5\% em Santa Maria Madalena. A de Quissamã prevê o mesmo percentual de $10 \%$, porém, restrito a um colégio cenecista, também privilegiado em outras LOs, como as de Miracema ("não menos" de 4\%!) e Santo Antônio de Pádua (até 3\%). Bastante generosa foi também a LO de Bom Jesus de Itabapoana com as filantrópicas ou comunitárias "comprovadamente sem fins lucrativos", destinando a elas "no mínimo" 3\% do percentual vinculado, e não o máximo de $3 \%$ fixado na CE.

Os vereadores de Petrópolis favoreceram instituições privadas ao estipular que a prefeitura poderia fornecer professores a escolas conveniadas ou alocar a verba necessária para o pagamento de professores da própria escola conveniada (parágrafo I do art. 157). Já a LO de Itatiaia prevê (art. 185) a possibilidade de se destinar até $5 \%$ dos 25\% (ou seja, I,25\% dos impostos) a bolsas de estudo, supostamente em escolas particulares, não especificando se seriam confessionais, filantrópicas ou comunitárias. 
A preocupação de evitar que a burocracia abocanhe uma grande fatia da verba levou os vereadores de Arraial do Cabo e Cachoeiras de Macacu a fixarem um percentual máximo a ser gasto com ela. A LO de Arraial determinou que a Secretaria de Educação e seus órgãos burocráticos não poderiam consumir mais do que 5\% das verbas da educação, e a de Cachoeiras estipulou 10\%.

$\mathrm{Na}$ elaboração do orçamento da educação, a LO de Volta Redonda foi talvez a única a prever a participação de todos os segmentos sociais envolvidos no processo educacional, porém, o prefeito entrou com recurso junto ao Tribunal de Justiça, que, em 1995, declarou o artigo inconstitucional. A LO de Resende é a única que prevê verba específica para cada escola, disposição seguida pela LO de Porto Real, depois de seu desmembramento.

Por último, a LO de São Gonçalo venceu o campeonato com o artigo que mais mudou (três vezes) desde a promulgação em 1990. $\bigcirc$ art. 175 original previa eleições diretas dos diretores, alterado, em 1993, para escolha pelo prefeito, modificado, em 1998, para eleições diretas, e, finalmente, alterado, em 2002, para escolha pelo prefeito.

\section{CONSIDERAÇÕES FINAIS}

Estas constatações indicam claramente:

a. o baixíssimo grau de exercício concreto da autonomia municipal numa perspectiva democrática, que, embora reivindicada e proclamada por adeptos das virtudes municipais (os defensores da municipalização do ensino, por exemplo), é muitas vezes meramente formal, não apenas porque a União e os estados têm poder muito maior, mas também porque as autoridades municipais não têm competência e/ ou interesse nesta autonomia, que só é reivindicada ou enfatizada em questões específicas (por exemplo, a descentralização dos recursos financeiros dos estados e da União ou a incapacidade de as prefeituras pagarem o piso nacional do magistério), não quando a participação da sociedade nas questões municipais - uma delas a elaboração da legislação municipal - está em questão.

b. a pouca ou nenhuma utilidade social e/ou legislativa dos vereadores, pois se limitaram a copiar, muitas vezes de modo incompetente, as 
disposições educacionais da CF e a CE e modelos fornecidos por consultoria ou partido político.

c. a nula ou insignificante influência dos profissionais da educação nas LOs, o que pode ser devido a: ( I ) pouco ou nenhum interesse, organização e participação; (2) descrença no poder da legislação de mudar para melhor a educação; (3) dificuldades criadas pelos vereadores e a burocracia das câmaras municipais para a participação da sociedade e dos profissionais na elaboração das LOs. Provavelmente, todos esses fatores se combinaram e ainda se combinam para explicar a escassa influência dos profissionais da educação nas LOs e na elaboração da legislação educacional.

Por fim, parece razoável supor que, se as disposições educacionais continham tantos equívocos e erros, o mesmo deve ocorrer no restante das LOs. Por isso, os vereadores poderão tomar a iniciativa de proceder à revisão de tais equívocos e, também, aproveitando a oportunidade, à atualização das LOs, para levar em conta as modificações introduzidas na Constituição Federal desde 1988 e nas legislações federal e estadual com incidência nas atribuições dos municípios. No caso das disposições educacionais das LOs, várias estão desatualizadas em razão dessas modificações. Por exemplo, a CF de 1988 previa que os municípios atuariam prioritariamente no ensino fundamental e no pré-escolar, atuação ampliada para a educação infantil pela Emenda Constitucional |4, de 1996.

\section{REFERÊNCIAS BIBLIOGRÁFICAS}

BOAVENTURA, E. M. A Educação nas leis orgânicas dos municípios baianos. In:

(Org.). Políticas municipais de educação. Salvador: UFBA/Fundação Clemente Mariani, 1996.

BRASIL. Congresso Nacional. Constituição da República Federativa do Brasil. Brasília, Senado Federal. Disponível em: <http://www.senado.gov.br> . Acesso em: fev. 2008.

BRASIL. Emenda constitucional n. 14, de 12 set. 1996. Modifica os arts. 34, 208, 2 I I e 2 I 2 da CF e dá nova redação ao art. 60 do ADCT (cria o Fundef). Brasília: Presidência da República. Disponível em: <http://www.planalto.gov.br>. Acesso em: out. 2005.

BRASIL. Lei n. 9.394, de 20 dez. 1996. Estabelece as diretrizes e bases da educação nacional. Brasilia: Presidência da República. Disponível em: <http://www. planalto.gov.br>. Acesso em: out. 2005. 
BRASIL. Lei n. 9.424, de 24 dez. 1996. Dispõe sobre o Fundef e dá outras providências. Brasilia: Presidência da República. Disponível em: <http://www.planalto.gov.br>. Acesso em: out. 2005.

CATANI, A.; OLIVEIRA, R. P. Leis orgânicas e educação em 20 municípios paulistas. Revista da Faculdade de Educação da USP, São Paulo, v. 19, n.2, p.257-274, jul./dez. 1993.

DAMASCENO, A.; CORREA, P. O Financiamento da educação nas leis orgânicas municipais paraenses. In: REUNIÃO ANUAL DA ANPED, 19., 1996, Caxambu. Anais... São Paulo: Anped, 1996. disquete (GT Estado e Política Educacional no Brasil: Comunicação)

RIO DE JANEIRO (Estado). Constituição do Estado do Rio de Janeiro de 1989: texto atualizado. 3. ed. Niterói: Imprensa Oficial, 200I. - Leis orgânicas dos 92 municípios fluminenses. Disponível em: < http://www.tce. rj.gov.br>. Acesso em: fev. 2008.

SANDANO, W. Lei orgânica municipal de 1990: educação e cidadania em Sorocaba. 1997. Tese (Doutorado) - Universidade Metodista de Piracicaba, Piracicaba.

SOUZA, D. B.; FARIA, L. C. M. de. Política, gestão e financiamento de sistemas municipais públicos de educação no Brasil: bibliografia analítica (1996-2002). Niterói: Intertexto; São Paulo: Xamã, 2005.

Recebido em: setembro 2009

Aprovado para publicação em: junho 2010 